\title{
Exploring the potential of seed flour from pigeon pea genotypes to retard the growth and development of Helicoverpa armigera
}

\author{
Sheetanshu Grover ${ }^{1}$, Satvir Kaur Grewal ${ }^{1 *}$, Anil Kumar Gupta ${ }^{1}$ and Gaurav Kumar \\ Taggar $^{2}$ \\ ${ }^{1}$ Department of Biochemistry, Punjab Agricultural University, Ludhiana (Punjab), INDIA \\ ${ }^{2}$ Department of Plant Breeding and Genetics, Punjab Agricultural University Ludhiana, (Punjab), INDIA \\ *Corresponding author. E-mail: satvir_pau@yahoo.co.in
}

Received: August 12, 2014; Revised received: September 13, 2014; Accepted: November 05, 2014

\begin{abstract}
Helicoverpa armigera is one of the most devastating known pest causing major economic losses. Development of insect resistance against chemical pesticides and the environment concerns are forcing researchers to pave way towards biopesticides. Our study aimed to test the efficacy of seed flour from ten pigeon pea genotypes against $H$. armigera development. $H$. armigera fed with diet containing pigeon pea seed powder exhibited larval and pupal weight reduction and certain abnormalities. Larval weight reduction varied from $19 \%$ (AL 1495) to $37 \%$ (AL 1677). Increase in larval duration was seen in genotypes containing higher trypsin inhibitor, phenols and phytic acid. $A L$ 1677 was found to be the most resistant genotype with $37 \%$ larval weight reduction followed by AL 1735. Larval-pupal intermediates were observed in diets containing AL 1495 and AL 1747 seed powder. The pupal weight reduction varied from $15.5 \%$ to $44.5 \%$. Results from this study suggest the inhibitory potential of Pls and other bioactive compounds such as phenols and phytic acid from pigeon pea cultivars against $H$. armigera development, that can be further exploited in pest management.
\end{abstract}

Keywords: Helicoverpa, Inhibitors, Insect, Pigeon pea, Proteases

\section{INTRODUCTION}

Helicoverpa armigera, a voracious feeder is the most destructive insect pest causing losses to economically important crop plants. It decreases crop yield by chewing leaves, flowers, green pods and developing seeds. Larval midgut contains a complex enzymatic system including trypsin, chymotrypsin, elastases and carboxypeptidases which help in protein digestion. Protease inhibitors (PIs), which are predominant in legume seeds, disrupt the growth and development of insect by interrupting protein digestion (Naseri et al., 2010, Shaikh et al., 2014). Health and environment hazards of synthetic pesticides along with developed resistance of insect towards chemical pesticides have made researchers to explore other ways to confer insect resistance (Kranthi et al., 2002). Pigeon pea (Cajanus cajan L.), a Fabaceae member is an important legume. The actual yield of pigeon pea does not meet the potential yield because of the insect attacks. PIs are present in significant amount in storage organs of plants, especially seeds (Mittal et al., 2014). Seeds of legumes also contain a number of secondary metabolites including polyphenols, flavonoids, lectins, enzyme inhibitors, and other antinutritional factors which interfere with the digestion process of insect affecting the metabolism, disrupting growth and development of the larva (Jadhav et al., 2012a). Mature seeds of pigeon pea have been shown to contain a number of antinutritional factors (Nwosu et al., 2013). Engineering plants with the protease inhibitors, amylase inhibitors and other defense related proteins is becoming a rage these days. This helps in strengthening the natural defense system of plants (Kuhar et al., 2012). It has been well documented that crude/purified protease inhibitor from different sources inhibit digestive enzymes such as trypsin and chymotrypsin which results in larval and pupal growth reduction (Naseri et al., 2010, Pandey et al., 2014). So far no pigeon pea genotype has been reported to be resistant towards $H$. armigera (Jadhav et al., 2012b). The objective of the present study was to test the efficacy of whole seed in flour form of ten pigeon pea genotypes containing different levels of PIs along with other antinutritional factors, against $H$. armigera and to find the tolerant genotypes.

\section{MATERIALS AND METHODS}

Seeds of ten pigeon pea genotypes AL 1770, AL 1495, AL 1747, AL 1735, AL 201, AL 15, AL 1755, AL 1677, AL 1753 and PAU 881 were procured from Department of Plant Breeding and Genetics, Punjab Agricultural University, Ludhiana, Punjab. Uniform fourth instar $H$. armigera larvae were weighed and 
then reared individually at $25{ }^{\circ} \mathrm{C}$ with $60 \%$ relative humidity in vials. Larvae were fed on artificial diet prepared according to Hamed and Nadeem (2008). The diet was mixed with equal amounts of seed powder of pigeon pea genotypes to test the efficacy against insect development (Fig.1). Diet was changed every day to avoid any microbial contamination. Change in larval weight was monitored every day till the formation of pupa. Afterwards, pupal weight was observed. The values were subjected to ANOVA using SPSS 16.0. Tukey's test was used to study significant differences between genotypes.

\section{RESULTS AND DISCUSSION}

There was an initial increase in weight of larvae up to 4 days when fed on artificial diet containing seed powder (Table 1). This could be due to initial assimilation of seed proteins. Physiological effect like general sluggishness along with reduction in weight was observed after 4 days of treatment. There was continuous reduction in larval weight with all the genotypes from fifth day onwards, except in AL 15, where the reduction in weight was observed on fourth day after treatment. Reduction in larval weight varied from $19 \%$ to $37 \%$ prior to pupa formation, among all the genotypes (Table 2). The minimum reduction in weight was observed in diet containing AL 1495 seed flour and maximum with AL 1677 seed flour. This weight reduction could be due to cumulative effect of varied content of protease inhibitors and other antinutritional factors present in seed flour. This result was supporting the in vitro results of our earlier study, where AL 1495 was shown to contain least amount of trypsin inhibitor units (114 TIU/g), lower phenolics $(0.28 \mathrm{mg} / \mathrm{g})$ and phytic acid $(0.32 \mathrm{mg} / \mathrm{g})$ content than AL 1677 (158 TIU/g, $0.43 \mathrm{mg} / \mathrm{g}$ and $0.44 \mathrm{mg} / \mathrm{g}$, respectively). A significant reduction $(\alpha=0.05)$ in larval weight and increase in mortality rate was observed when protease inhibitors from Capsicum annuиm, chickpea and kidney bean was incorporated in artificial diet for bioassay during feeding trials of $H$. armigera (Tamhane et al., 2005; Kansal et al., 2008; Mittal et al., 2014). In a study to test, the efficacy of phenolics on growth and survival of $H$. armigera and Spodoptera litura, rutin was found to cause inhibition of $H$. armigera larvae which might be due to its interference with the prothoracicotrophic hormone and ecdysteroid action, thus, affecting molting process (Curtis et al., 1984; Jadhav et al., 2012a). Polyphenolics, tannins in particular, offer resistance against herbivory by forming complex, denaturing and precipitating proteins including digestive enzymes (MacManus et al., 1985). There was found a positive correlation $(\mathrm{r}=0.46)$ between the gut protease inhibition and total phenols present in these genotypes (data not given for total phenols, Table 3). Thus, gut protease inhibition and larval weight reduction can be attributed to the interference of inhibitors and phenolic

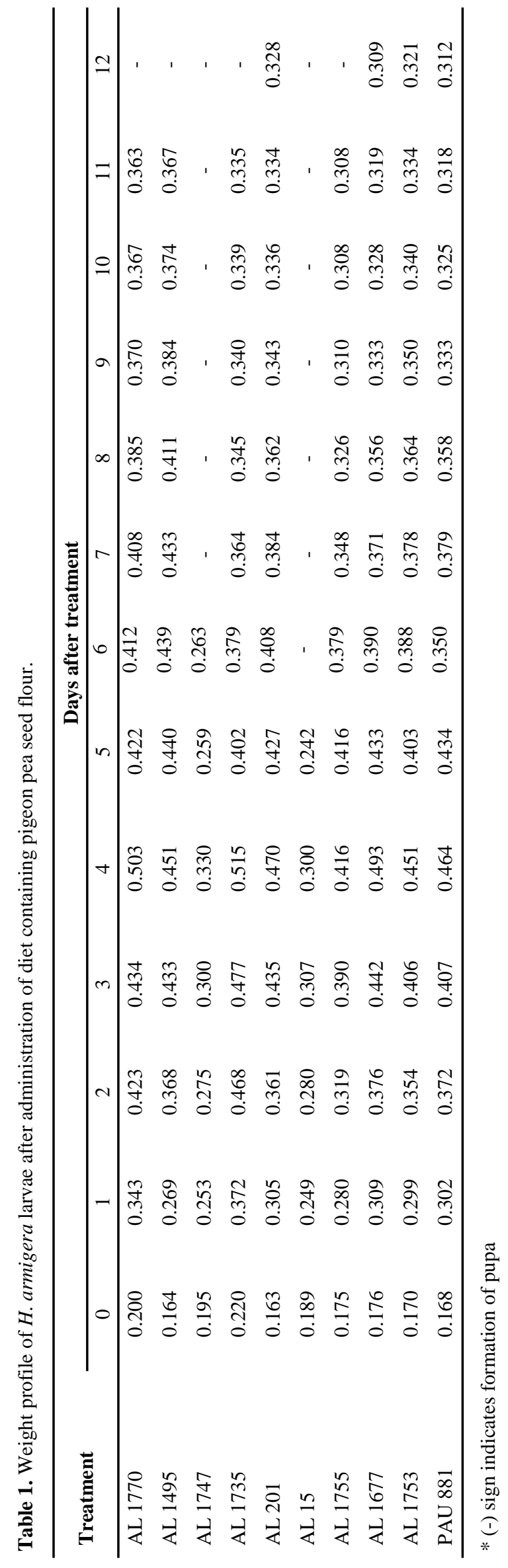


Table 2. Effect of pigeon pea protease iuhibitors on growth and development of H. armigera.

\begin{tabular}{lccccc}
\hline Genotype & $\begin{array}{c}\text { Larval weight } \\
\text { reduction (\%) }\end{array}$ & $\begin{array}{c}\text { Larval-pupal } \\
\text { intermediates } \\
\text { formed }\end{array}$ & $\begin{array}{c}\text { Malformed } \\
\text { pupae }\end{array}$ & Pupal mortality & $\begin{array}{c}\text { Pupal weight reduction } \\
(\%)\end{array}$ \\
\hline AL 1770 & $28.0^{\mathrm{b}}$ & - & - & + & $44.5^{\mathrm{f}}$ \\
AL 1495 & $19.0^{\mathrm{a}}$ & + & - & - & $17.5^{\mathrm{ab}}$ \\
AL 1747 & $20.0^{\mathrm{a}}$ & + & + & + & $30.5^{\mathrm{d}}$ \\
AL 1735 & $34.5^{\mathrm{de}}$ & - & + & + & $55.5^{\mathrm{g}}$ \\
AL 201 & $30.5^{\mathrm{bcd}}$ & - & + & + & $42.0^{\mathrm{ef}}$ \\
AL 15 & $21.0^{\mathrm{a}}$ & - & - & - & $24.0^{\mathrm{c}}$ \\
AL 1755 & $26.5^{\mathrm{b}}$ & - & + & + & $39.5^{\mathrm{e}}$ \\
AL 1677 & $37.0^{\mathrm{e}}$ & - & - & - & $16.0^{\mathrm{ab}}$ \\
AL 1753 & $29.0^{\mathrm{bc}}$ & - & - & - & $15.5^{\mathrm{a}}$ \\
PAU 881 & $33.0^{\text {cde }}$ & - & + & + & $19.5^{\mathrm{b}}$ \\
\hline Mean & 28.0 & & & & 30.45 \\
\hline
\end{tabular}

*Different letters show statistical differences among used genotypes (Tukey' test, $\alpha=0.05)$. *(+) indicates presence and $(-)$ indicates absence

Table 3. Correlation between per cent gut protease inhibition, trypsin inhibitor status, phenolic content, larval weight reduction and number of days taken to form pupa.

\begin{tabular}{lcccc}
\hline & $\begin{array}{c}\text { Trypsin inhibitor } \\
\text { content }\end{array}$ & $\begin{array}{c}\text { Total } \\
\text { phenols }\end{array}$ & $\begin{array}{c}\text { Larval weight } \\
\text { reduction }\end{array}$ & No. of days to form pupa \\
\hline $\begin{array}{l}\text { \% gut proteases } \\
\text { inhibition }\end{array}$ & 0.61 & 0.46 & 0.6 & 0.46 \\
\hline
\end{tabular}

compounds present in seed flour with the insect proteases. Positive correlation $(r=0.6)$ between larval weight reduction and inhibition of gut proteases was observed (data not given), which justifies the possible role of inhibition of gut proteases resulting in limited availability of amino acids for larval growth. It could also be due to hyperproduction of gut proteases by larvae in response to protease inhibitors present in diet that exerted insect for energy and essential amino acids, leading to retarded growth (Naseri et al., 2010). Phytic acid incorporated in diet leads to larval weight reduction and mortality in Depressaria pastinacella and Trichoplusiani insects (Green et al., 2001). This might be due to the interruption of the metabolism in larvae as phytic acid acts as metal ion and protein chelator. The body was further found to be paralysed with dark brown to black skin and green colour was observed in the leg region of the mid gut segments in AL 1495 and AL 1735. Gradually, whole body turned brownish to black leaving a slight faded portion in the posterior part though the legs were all black and paralysed. With time, dry appearance of body, crumpled skin, overall shrinkage of body segments and reduction due to shortening of body segments was observed in all the ten genotypes. Abnormality in molting and subsequent death was observed in some larvae under treatment with AL 1747 and AL 1755. Larval-pupal intermediates were observed in diets containing AL 1495 and AL 1747 seed powder (Fig. 2). The number of days taken to form pupa was found to vary within genotypes. AL 15 and AL 1747 were the earliest genotypes to form pupa, 5 and 6 days after treatment, respectively. The pupae formed were smaller in size in genotypes with earlier pupa formation (Fig. 2). Inspite of being insignificant there was found positive correlation $(r=0.46)$ between per cent gut protease inhibition and number of days taken to form pupa. This increase in larval duration can be explained by the physiological changes in larvae due to the presence of bioactive compounds in seed flour. It may be due to the interference of trypsin inhibitors and phenolics present in mature seed with the molting process, which resulted in delayed development. Actually proteins located in insect cuticle are essential for the production of new adult tissues and enzymes. These proteins are synthesized from free amino acids following a reorganization of peptides without amino acids degradation. Serine and cysteine proteinases are involved in proteolytic activity which is required in this reorganization. It might be due to interference of inhibitors with this proteolytic activity or result in elevated proteinases production, thus limiting the number of amino acids (Pandey et al., 2014). Reduction in pupal weight varied from $15.5 \%$ (AL 1753) to $55.5 \%$ (AL 1735). This suggests the possible interference of bioactive compounds present in these genotypes with metabolism, resulting in weight reduction due to starvation. Malformed pupae could be seen in some treatments (AL 1770, AL 1747, AL 1735, AL 201, AL 1755 and PAU 881), which 

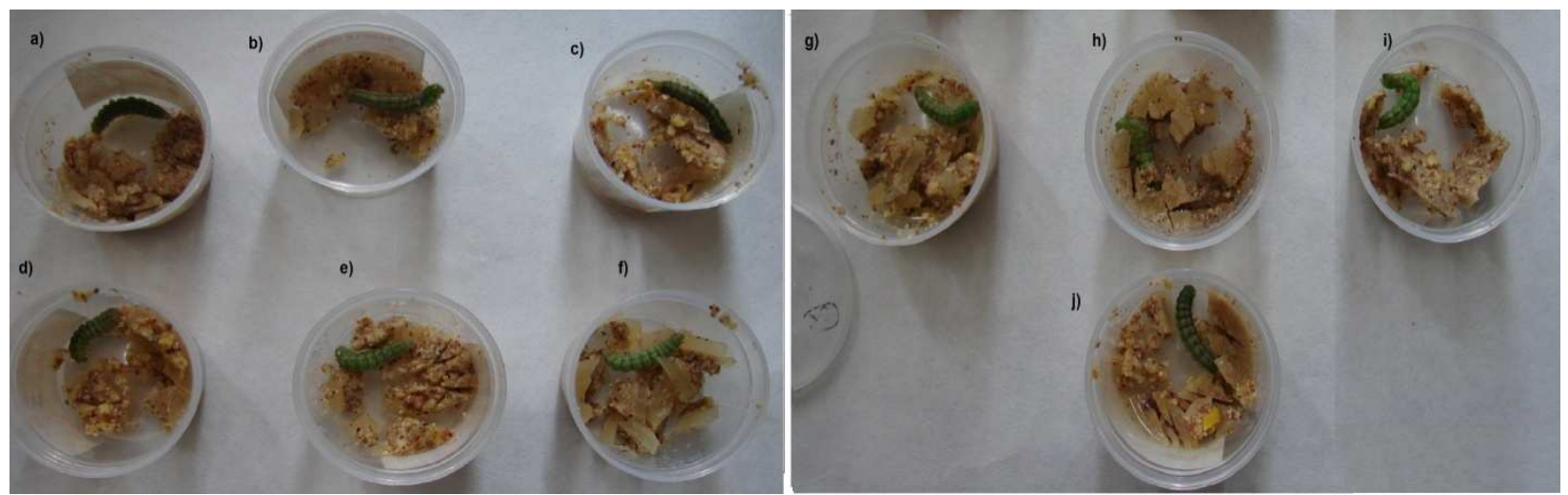

Fig. 1. Larvae fed on artificial diet with seed powder from different genotypes ( $a=A L 1770, b=A L 1495, c=A L 1747, d=A L$ 1735, $e=A L 201, f=A L 15, g=A L 1755, h=A L 1677, i=A L 1753, j=P A U ~ 881)$.
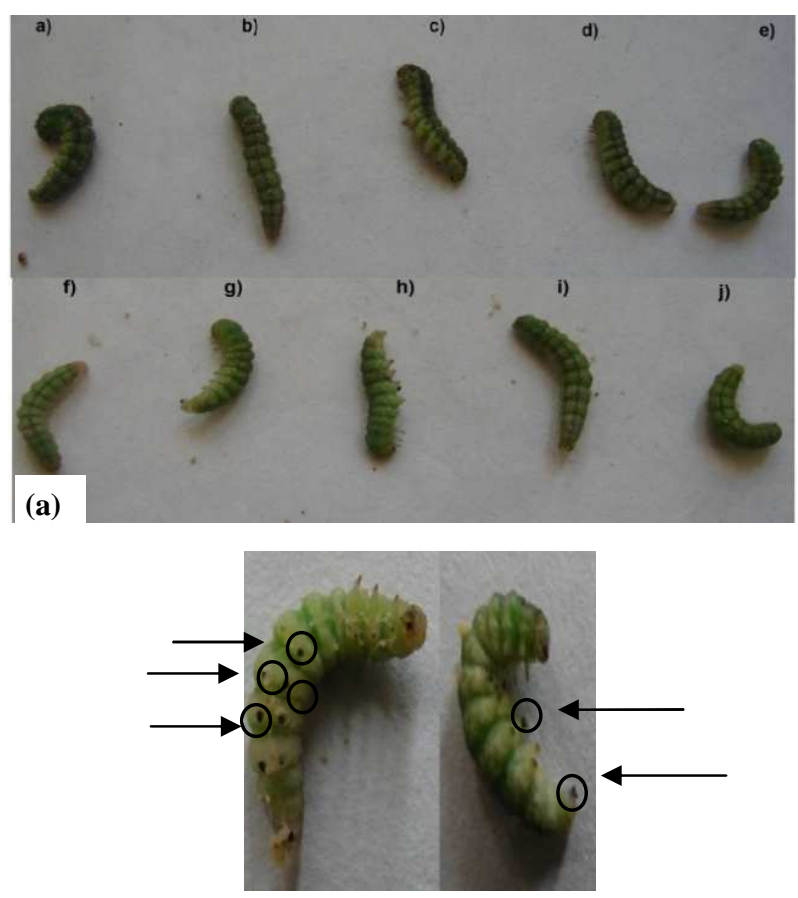

Black feet of larvae observed
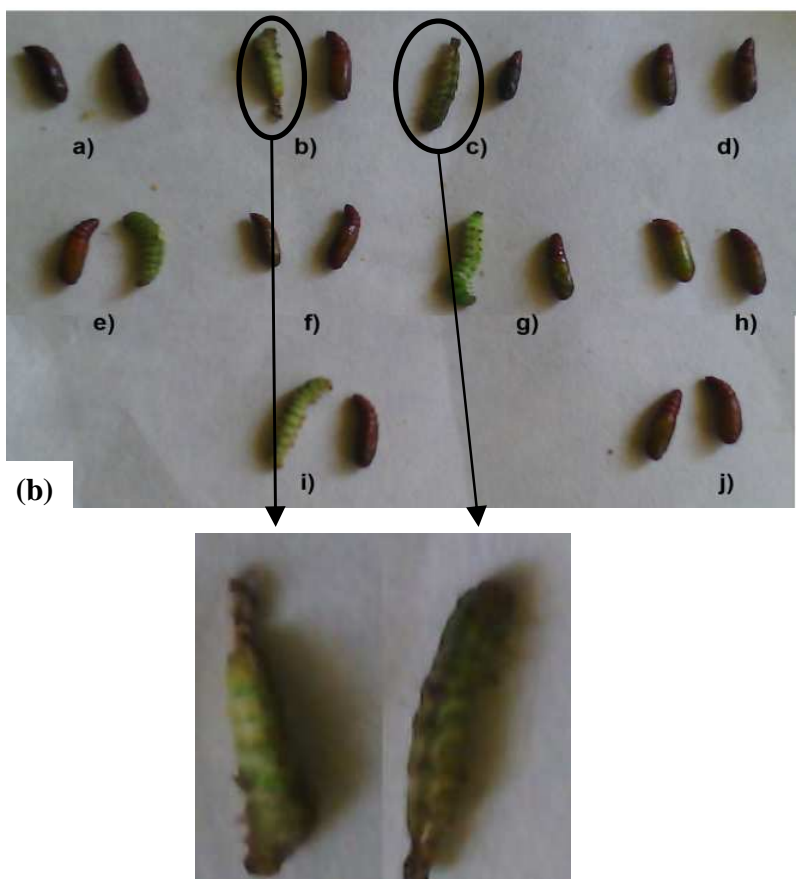

Larval-pupal intermediates

Fig. 2. Variations and certain abnormalities observed in larvae and pupae formed under different treatments.

possess comparatively higher TI content. In general, pupal mortality was observed where pupal weight reduction was higher (Table 2). The resulting pupal weight reduction and pupal mortality is due to insufficient nutrient accumulation during the larval stage, which is crucial for assimilation of food and energy required for development. Tamhane et al. (2005) observed delay (3-8 days) in pupae formation, reduction in pupal weight and increase in formation of malformed pupae in PI-fed larvae compared to control. Kidney bean purified trypsin inhibitor incorporated in artificial diet has been shown to significantly $(\alpha=0.05)$ increase the larval and pupal duration of $H$. armigera when added to the artificial diet. The workers found the significant difference $(\alpha=0.05)$ of 3 days and 1 day in larval and pupal duration, respectively between control and inhibitor containing diets (Mittal et al., 2014). Udamale et al. (2013) reported that factors other than trypsin like protease might also be susceptible to inhibition by pigeon pea inhibitors in the in vivo assays, which led to retarded growth and development of larvae. Instead of purified inhibitors, we used seed powder which would give clear picture of potential of mature seeds of the pigeon pea genotypes against the $H$. armigera.

\section{Conclusion}

The present study concluded that all the genotypes possess the potential to affect growth and development processes of $H$. armigera. Interference of various bioactive components present in seed powder with the gut enzyme system starve the insects of required nutrition and is responsible for starvation and delay in metamorphosis. Presence of higher amount of antinutritional factors in seed flour might be responsible for delaying the process of development in 
larvae, suggesting some metabolic inference in larvae. This delay in larval period can be used as a tool to provide resistance against the insect damage. AL 1677 was found to be the most resistant genotype with $37 \%$ larval weight reduction followed by AL 1735. The study can be further explored to determine the status of various secondary metabolites responsible for the resistance.

\section{REFERENCES}

Curtis, A.T., Hori, M., Green, J.M., Wolfgang, W.J., Hiruma, K. and Riddiford, L. (1984). Ecdysteroid regulation of the onset of cuticular melanization in all atectomized and black mutant Manduca sexta larvae. Journal of Insect Physiology, 30: 597-606.

Green, E.S., Zangerl, A.R. and Berenbaum, M.R. (2001). Effects of phytic acid and xanthotoxin on growth and detoxification in caterpillars. Journal of Chemical Ecology, 27:1763-1773.

Hamed, M and Nadeem S. (2008). Rearing of Helicoverpa armigera (Hub.) on artificial diets in Laboratory. Pakistan Journal of Zoology, 40: 447-450.

Jadhav, D.R., Mallikarjuna, N., Rathore, A. and Pokle, D. (2012a). Effect of some flavonoids on survival and development of Helicoverpa armigera (Hubner) and Spodoptera litura (Fab) (Lepidoptera: Noctuidae). Asian Journal of Agricultural Sciences, 4: 298-307.

Jadhav, D.R., Mallikarjuna, N., Sharma, H.C. and Saxena, K. B. (2012b). Introgression of Helicoverpa armigera resistance from Cajanus acutifolious-a wild relative from secondary gene pool of pigeon pea (Cajanus cajan). Asian Journal of Agricultural Sciences, 4: 242248.

Kansal, R., Kumar, M., Kuhar, K., Gupta, R.N., Subrahmanyam, B., Koundal, K.R. and Gupta, V.K. (2008). Purification and characterization of trypsin inhibitor from Cicer arietinum L. and its efficacy against Helicoverpa armigera. Brazilian Society of Plant Physiology, 20: 313-322.

Kranthi, K.R., Jadhav, D.R., Kranthi, S., Wanjari, R.R., Ali, S.S. and Russell, D.A. (2002) Insecticide resistance in five major insect pests of cotton in India.Crop Protection, 21: 449-460.

Kuhar, K., Kansal, R., Mishra, A., Koundal, K.R. and Gupta,
V.K. (2012). Cloning, characterization and expression analysis of a novel gene encoding Kunitz-type protease inhibitor from Dolichos biflorus. 3 Biotechnology, 2: 199-209.

MacManus, J.P., Davis, K.G., Beart, J.E., Goffney, S.H., Lilley, T.H. and Haslam, E. (1985). Polyphenol interaction. Part 1. Introduction: Some observations on the reversible complexation of polyphenols with proteins and polysaccharides. Journal of Chemistry Society Perkin Transactions, 2:1429-1438.

Mittal, A., Kansal, R., Kalia, V., Tripathi, M. and Gupta, V.K. (2014). A kidney bean trypsin inhibitor with an insecticidal potential against Helicoverpa armigera and Spodoptera litura. Acta Physiologiae Plantarum, 36: 525-539.

Naseri, B., Fathipour, Y., Moharramipour, S., Hosseininaveh, V. and Gatehouse, A.M.R. (2010). Digestive proteolytic and amylolytic activities of Helicoverpa armigera in response to feeding on different soybean cultivars. Pest Management Science, 66: 1316-1323.

Nwosu, J.N., Ojukwu, M., Ogueke, C.C., Ahaotu, I. and Owuamanam, C.I. (2013). The antinutritional properties and ease of dehulling on the proximate composition of pigeon pea (Cajanus cajan) as affected by malting. International Journal of Life Sciences, 2: 60-70.

Pandey, P.K., Singh, D., Singh, S., Khan, M.Y. and Jamal, F. (2014). A nonhost peptidase inhibitor of $\sim 14 \mathrm{kDa}$ from Butea monosperma (Lam.) Taub. seeds affects negatively the growth and developmental physiology of Helicoverpa armigera. Biochemistry Research International, 2014:1-11.

Shaikh, F.K., Gadge, P.P., Shinde, A.A., Padul, M.V. and Kachole, M.S. (2014). Characterization of the AITI13 protein from Indian siris (Albizia lebbeck) that inhibits the growth of cotton bollworm (Helicoverpa armigera). Journal of Asia Pacific Entomology, 17: 319-325.

Tamhane, V.A., Chougule, N.P., Giri, A.P., Dixit, A.R., Sainani, M.N. and Gupta, V.S. (2005). In vivo and in vitro effect of Capsicum annum proteinase inhibitors on Helicoverpa armigera gut proteinases. Biochimica et Biophysica Acta, 1722: 156-167.

Udamale, S.K., Moharil, M.P., Ugale, T.B. and Mankar, J.M. (2013). Differential inhibition of Helicoverpa armigera (Hubner) gut proteinases by proteinase inhibitors of okra and it's wild relatives. ISRN Biotechnology, 2013: 1-10. 